\title{
Gambaran Mindfulness pada Atlet Senam Artistik Putri Jawa Timur
}

\author{
ALYA AFANI \& AFIF KURNIAWAN* \\ Departemen Psikologi Klinis dan Kesehatan Mental, Fakultas Psikologi Universitas Airlangga
}

\begin{abstract}
ABSTRAK
Teori ironic mental processes menjelaskan tantangan yang sering dihadapi atlet elit yakni kesulitan mengontrol proses kognitif meski telah melakukan upaya mental sebelumnya yang dapat menyebabkan adanya penurunan performa. Mindfulness, yang merupakan kondisi kesadaran dimana individu memberi perhatian secara utuh, dengan niat yang jelas, dan tidak memberi penilaian pada pengalaman masa kini dari momen ke momen, dapat membantu mencegah adanya efek yang merugikan dari proses mental ironis. Penelitian bertujuan memberikan gambaran mindfulness pada atlet senam artistik putri Jawa Timur menggunakan metode kualitatif dengan pendekatan studi kasus intrinsik yang melibatkan dua partisipan. Teknik analisis data menggunakan analisis tematik dengan theory driven. Hasil penelitian menunjukkan bahwa kedua partisipan mampu untuk mindful ketika sesaat sebelum tampil, saat tampil di pertandingan, saat harus menghadapi trauma terkait dengan gerakan senam, maupun saat menjalani masa rehabilitasi pasca cedera. Namun, keduanya menunjukkan adanya inkonsistensi dalam usahanya menjadi mindful, baik ketika berlatih maupun bertanding.
\end{abstract}

Kata kunci: atlet, mindfulness, senam

\begin{abstract}
Ironic mental processes theory explains the challenge faced by elite athletes on how to control their cognitive process despite investing in mental effort which can cause performance-decrease. Mindfulness is a state of awareness which arises by paying close attention, on purpose, and non-judging to the present moment, can help prevent the detrimental effects of ironic mental processes. This study aims to provide an overview of mindfulness on woman artistic gymnastics athletes in East Java, used qualitative methods with intrinsic case study approach which involved two participants. Thematic analysis with theory-driven approach was used to analyze the data. The results of this study shown both participants are capable to be mindful that can be seen from right before performing, when performing, when dealing with the trauma related to the acrobatics, and during the post-injury rehabilitation. However, there are some inconsistency on both participants to become mindful.
\end{abstract}

Keywords: athlete, gymnastics, mindfulness

Buletin Penelitian Psikologi dan Kesehatan Mental (BRPKM), 2021, Vol. 1(1), 406-416

*Alamat korespondensi: Fakultas Psikologi Universitas Airlangga, Kampus B Universitas Airlangga Jalan Airlangga 4-6 Surabaya 60286. Surel: afif.kurniawan@psikologi.unair.ac.id Naskah ini merupakan naskah dengan akses terbuka dibawah ketentuan the Creative Common Attribution License (CC-BY-4.0) (http://creativecommons.org/licenses/by/4.0), sehingga penggunaan, distribusi, reproduksi dalam media apapun atas artikel ini tidak dibatasi, selama sumber aslinya disitir dengan baik. 


\section{PEN D A H U L U A N}

Senam artistik merupakan disiplin senam yang menggabungkan aspek akrobatik dan kalistenik dengan tujuan untuk mendapatkan efek yang artistik dari gerakan-gerakan senam yang dilakukan (Sukamti \& Hidayat, 2010). Senam artistik putri terdiri atas 4 alat, yaitu lantai, meja lompat, balok keseimbangan, dan palang bertingkat (Aka, 2009). Banyaknya variasi alat yang memiliki beban yang berbeda-beda ini menuntut atlet untuk mampu mengkoordinasikan kekuatan otot pada bagian tubuh tertentu dalam melakukan gerakan pada alat yang berbeda-beda dengan tingkat kesulitan yang berbeda-beda pula.

Senam secara konsisten menduduki peringkat paling atas, dibandingkan dengan olahraga wanita lainnya, yang memiliki tingkat resiko cedera yang tinggi (Meeusen \& Borms, 1992; Kerr dkk., 2015). Sebagai olahraga wanita yang memiliki rata-rata tingkat resiko cedera yang tertinggi ini dapat memicu munculnya rasa takut akan cedera pada atlet yang dapat berpotensi mengganggu perhatian atlet dan dapat menghambat performa atlet (Chase dkk., 2005). Heil (1993 dalam Chase dkk., 2005) memaparkan bahwa rasa takut akan cedera dapat mengarah pada adanya konsekuensi secara fisiologis dan psikologis yang dapat berdampak negatif pada performa atlet serta meningkatkan resiko terjadinya cedera. Resiko akan terjadi cedera juga dapat meningkat seiring dengan meningkatnya tingkat keterampilan yang harus diasah oleh atlet (Meeusen \& Borms, 1992 dalam Chase dkk., 2005).

Atlet elit kerap dihadapkan dengan berbagai tantangan dalam menjalankan kehidupan sebagai atlet. Tantangan-tantangan yang ditemui ini dapat berpotensi menyebabkan performa atlet menurun, baik saat berlatih maupun bertanding. Di Jawa Timur sendiri, atlet senam artistik putri yang berada di bawah naungan PERSANI Jawa Timur mengalami adanya penurunan prestasi dalam kurun waktu lima tahun terakhir. Sebagai atlet profesional, atlet sudah seharusnya berusaha untuk memberikan penampilan terbaiknya terutama ketika bertanding. Namun, dalam usahanya untuk menampilkan performa yang baik ini dapat terhambat oleh adanya penghambat psikologi yang bersifat non-patologis (Birrer dkk., 2012). Birrer, Röthlin, dan Philipp (2012) menjelaskan lebih lanjut bahwa keadaan psiko-fisiologis yang optimal dapat mendukung atlet untuk menampilkan performa yang baik. Faktor penghambat yang dapat mempengaruhi performa atlet dalam berkompetisi dapat berupa kecemasan dalam berkompetisi, rasa takut akan kegagalan, adanya ekspektasi yang tidak realistis yang disebabkan oleh kepribadian yang perfeksionis atau adanya cedera, perilaku menghindar, serta amarah dan emosi negatif lainnya (Birrer dkk., 2012). Selain itu, terdapat faktor-faktor lain yang dapat memberi pengaruh negatif, yakni faktor personal yang dapat berupa atribusi kegagalan internal serta gaya koping penghindaran (avoidance coping style) dan faktor lingkungan yang dapat berupa latihan yang berlebihan (overtraining), kesulitan dalam menyeimbangkan hidup (life-balance difficulties), serta adanya permasalahan internal (Birrer dkk., 2012).

Birrer, Röthlin, dan Philipp (2012) memaparkan lebih lanjut bahwa proses mental ironis sebagian besar terkait dengan adanya pengendalian diri yang disengaja dari proses atau keadaan psikologis, seperti pemikiran, emosi, perilaku, dan sensasi tubuh, untuk mencapai tujuan personal tertentu. Hal ini dapat mengakibatkan menurunnya performa atlet yang disebabkan oleh berfokus pada tugas-tugas yang tidak relevan, seperti lebih berfokus pada pemikiran dan perasaan (Birrer dkk., 2012). Masters dan Maxwell (2008 dalam Josefsson dkk., 2019) menyatakan bahwa bentuk perhatian yang berfokus pada diri sendiri pada gerakan otomatis serta upaya untuk mengontrolnya juga dikaitkan dengan adanya penurunan performa olahraga. Birrer, Röthlin, dan Philipp 2012) menyatakan bahwa mindfulness dapat membantu dalam mencegah adanya efek yang merugikan dari proses mental ironis.

Mindfulness merupakan keadaan sadar yang muncul dari usaha untuk memperhatikan, dengan niat yang jelas, dan tanpa memberikan penilaian pada suatu pengalaman dari momen ke momen (Kabat-Zinn, 
2013). Brown dan Ryan (2003) menyatakan bahwa mindfulness merupakan kesadaran individu yang terbuka dan merupakan kondisi dimana individu memperhatikan secara utuh terhadap apa yang terjadi. Sedangkan Baer, Smith, Hopkins, Krietemeyer, dan Toney (2006) mendefinisikan mindfulness sebagai suatu proses dimana kesadaran individu meningkat dengan berfokus pada pengalaman saat ini serta adanya penerimaan tanpa memberikan penilaian terhadap pengalaman tersebut. Kabat-Zinn (2013) menyatakan bahwa mindfulness terdiri atas tujuh sikap dasar, yakni non-judging (tidak memberikan penilaian), patience (sabar), beginner's mind (pemikiran orang awam), trust (kepercayaan), non-striving (tidak berusaha), acceptance (penerimaan), dan letting go (melepaskan/tidak terikat).

Mindfulness dapat dikonseptualisasikan sebagai keadaan yang dapat dipraktikkan dalam bentuk meditasi atau dengan pelatihan mindfulness (mindfulness training) maupun sebagai bentuk trait psikologis yang terkait dengan kecenderungan individu untuk menjadi mindful dalam menjalani kesehariannya (Lau dkk., 2006; Baer dkk., 2006 dalam Kaiseler dkk., 2017). Bukti-bukti ilmiah menunjukkan bahwa tanpa adanya intervensi mindfulness yang diberikan sebelumnya, trait mindfulness nampak stabil seiring berjalannya waktu (Baer dkk., 2006 dalam Kaiseler dkk., 2017). Kaiseler, Poolton, Backhouse, dan Stanger (2017) menjelaskan lebih lanjut bahwa pemberian latihan mindfulness secara formal maupun informal mengarah kepada adanya disposisi mindful (mindful disposition) yang lebih besar. Dispositional mindfulness sendiri mengacu pada kemampuan individu untuk mempertahankan kontrol baik dalam konteks adanya peristiwa yang bermasalah, kognisi, maupun perasaan.

Mindfulness telah dikaitkan dengan sejumlah hasil studi yang menyatakan bahwa mindfulness memiliki pengaruh yang positif terhadap flow dispositions, penggunaan keterampilan psikologis yang lebih besar (seperti, self-talk), serta adanya peningkatan kesejahteraan psikologis (Kee \& Wang, 2008; Vidrine dkk., 2015; Weinstein dkk., 2009 dalam Kaiseler dkk., 2017). Selain itu, mindfulness juga secara umum dapat meningkatkan kesehatan mental dan kesejahteraan psikologis, dan secara spesifik dapat menurunkan kecemasan, depresi, dan stres, serta dapat meningkatkan keterampilan individu dalam memanajemen stres (Kabat-Zinn, 1990; Zimmaro dkk., 2016 dalam Kaiseler dkk., 2017). Hubungan antara mindfulness dengan variabel-variabel lain yang telah disebutkan di atas ditemukan baik dalam konsep mindfulness sebagai suatu keadaan yang mengacu pada pelatihan berbasis meditasi maupun konsep mindfulness sebagai trait (sifat) yang mengacu pada kecenderungan individu untuk mindful dalam kehidupan sehariharinya (Bao dkk., 2015; Chiesa \& Serretti, 2009; Harrington dkk., 2014; Hofmann dkk., 2010; Weinstein dkk., 2009 dalam Kaiseler dkk., 2017).

Pemberian pelatihan mindfulness baik secara formal maupun informal dapat mengarah pada semakin besarnya dispositional mindfulness (Kaiseler dkk., 2017). Birrer, Röthlin, dan Philipp (2012) menjelaskan lebih lanjut bahwa formal mindfulness practice (praktis formal mindfulness) dengan menggunakan bare-attention, intensi untuk regulasi diri, dan sikap tidak memberikan penilaian (nonjudgemental) dan menerima akan meningkatkan tingkat dispositional mindfulness pada individu untuk bertindak dengan lebih perhatian dan tidak memberikan penilaian pada kehidupan sehari-harinya. Tanpa adanya intervensi mindfulness yang diberikan sebelumnya, trait mindfulness sendiri akan cenderung stabil seiring berjalannya waktu (Baer dkk., 2006 dalam Kaiseler dkk., 2017).

Penelitian ini berusaha untuk memberikan gambaran mindfulness pada atlet senam artistik putri Jawa Timur yang diharapkan dapat berguna untuk menambah sumbangan ilmu pengetahuan. Selain itu, diharapkan hasil dari penelitian ini dapat menjadi masukan atau referensi untuk pelatih dalam membuat program latihan untuk atletnya. 


\section{Desain Penelitian}

\section{MET ODE}

Metode penelitian yang digunakan dalam penelitian ini adalah metode kualitatif yang bertujuan untuk memahami manusia sebagai makhluk yang subjektif beserta kompleksitasnya secara terperinci (Poerwandari, 2007). Pendekatan yang digunakan adalah studi kasus intrinsik. Pendekatan studi kasus sendiri bersifat komprehensif, rinci, mendalam, dan lebih ditujukan untuk menelaah fenomena yang kontemporer (Herdiansyah, 2015). Pendekatan studi kasus intrinsik dalam penelitian ini digunakan untuk memahami secara mendalam mengenai gambaran mindfulness yang terjadi pada atlet senam artistik putri Jawa Timur.

\section{Partisipan}

Penelitian menggunakan teknik purposive sampling dalam menentukan partisipan, yakni teknik pemilihan partisipan yang memiliki karakteristik tertentu sehingga memungkinkan untuk dilakukan eksplorasi dan memahami secara rinci terkait dengan topik penelitian (Ritchie dkk., 2003). Partisipan dalam penelitian ini berjumlah 2 orang perempuan berusia 23 dan 24 tahun. Partisipan dipilih berdasarkan kriteria yang telah ditentukan, yakni atlet senam artistik putri yang berada di bawah naungan PERSANI Jawa Timur, berusia 20 - 25 tahun, pernah mengikuti kompetisi tingkat daerah, nasional, dan internasional, serta bersedia diwawancarai lebih lanjut yang dinyatakan secara tertulis dengan informed consent.

\section{Strategi Pengumpulan Data}

Teknik penggalian data dilakukan menggunakan wawancara secara mendalam menggunakan pedoman umum. Wawancara mendalam merupakan proses penggalian data yang dilakukan oleh pewawancara dan responden melalui proses tanya jawab yang didalamnya memuat obrolan dengan tujuan tertentu (Legard dkk., 2003). Elaborasi pertanyaan juga dilakukan saat wawancara berlangsung untuk menggali data dengan lebih mendalam.

\section{Analisis Data}

Teknik analisis data menggunakan analisis tematik dengan pendekatan theory driven. Analisis tematik digunakan untuk menyusun hasil penelitian secara sistematis untuk meningkatkan sensitivitas dan keakuratan dalam memahami dan menginterpretasi data dengan cara mengidentifikasi tema-tema yang kemudian akan membentuk pola pada suatu fenomena (Boyatzis, 1998). Lebih lanjut, Boyatzis (1998) menjelaskan bahwa pendekatan theory driven merupakan teknik analisis data yang penemuan temanya dilakukan dengan cara membuat kode berdasarkan teori yang telah ada sebelumnya, yang kemudian akan diformulasikan sesuai dengan dimensi serta indikator yang ada.

\section{HAS I L P E N EL I T IAN}

Kedua partisipan dalam penelitian ini tergabung sebagai atlet senam artistik putri di bawah naungan PERSANI Jawa Timur. Partisipan 1 (LF) berusia 24 tahun, sedangkan partisipan 2 (TM) berusia 23 tahun. Keduanya berasal dari Surabaya. Partisipan LF telah menyelesaikan pendidikannya di tingkat S1, sedangkan partisipan TM masih dalam proses menyelesaikan studi pada jenjang S1. Kedua partisipan telah mengikuti olahraga senam sejak usia dini, yakni pada usia 5 tahun untuk partisipan LF dan usia 8 tahun untuk partisipan TM. Partisipan LF menggeluti bidang senam selama 19 tahun, sedangkan partisipan TM telah berkarir sebagai atlet selama 15 tahun. Pertandingan terakhir yang diikuti oleh partisipan 1 adalah SEA Games 2019, sedangkan pertandingan terakhir yang diikuti partisipan 2 adalah Asian Games 2018 serta test event untuk SEA Games 2019.

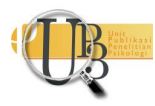


Mindfulness terdiri atas 7 sikap dasar, yakni non-judging (tidak memberikan penilaian), patience (sabar), beginner's mind (pemikiran orang awam), trust (kepercayaan), non-striving (tidak berusaha), acceptance (penerimaan), dan letting go (melepaskan/tidak terikat) (Kabat-Zinn, 2013). Berdasarkan hasil penelitian ini, menunjukkan bahwa ketujuh sikap dasar ini muncul pada kedua partisipan. Pada saat bertanding, kedua partisipan mampu untuk berfokus melakukan gerakan satu per satu tanpa berusaha untuk mendapatkan hasil dari tujuan tertentu dan tidak memberikan ekspektasi terhadap nilai maupun penampilannya. Selama melakukan rangkaian gerakan, yang dipikirkan kedua partisipan adalah visualisasi gerakan per gerakan. Saat gagal melakukan gerakan atau terjatuh di pertandingan, kedua partisipan mampu untuk tetap fokus melanjutkan gerakan-gerakan selanjutnya meski sebelumnya telah terjatuh atau gagal mengambil gerakan. Keduanya juga mampu untuk tidak memberikan penilaian-penilaian terhadap apa yang terjadi.

Saat terjatuh atau gagal mengambil gerakan, kedua partisipan mampu untuk tetap percaya akan kekuasaan diri dan kemampuan dirinya untuk menyelesaikan rangkaian gerakan hingga akhir. Keduanya juga mampu untuk tetap tenang dan tidak tergesa-gesa dalam menyelesaikan gerakan walau sebelumnya gagal mengambil gerakan atau terjatuh. Selain itu, keduanya mampu untuk tidak melakukan penolakan maupun penyangkalan ketika sempat terjatuh atau gagal melakukan gerakan di pertadingan. Meski begitu, dalam beberapa kesempatan, kedua partisipan pernah melakukan gerakan tanpa sadar baik ketika di pertandingan maupun saat berlatih. Partisipan LF pernah melakukan gerakan tanpa sadar yang mengakibatkan ia mengalami cedera dan juga trauma terhadap gerakan yang mengarah ke belakang, sedangkan partisipan TM mengatakan bahwa beberapa kali ia pernah melakukan gerakan secara tidak sadar dan hasilnya terkadang bisa berhasil namun juga bisa gagal.

\section{I S K U S I}

Mindfulness merupakan kondisi kesadaran yang muncul dari adanya usaha untuk memperhatikan, dengan niat yang jelas, serta tidak memberikan penilaian pada suatu pengalaman dari momen ke momen di masa kini (Kabat-Zinn, 2013). Kabat-Zinn (1994 dalam Giluk, 2009) menyebutkan bahwa mindfulness terdiri atas perhatian yang disengaja dan kesadaran atas masa kini, dengan menunjukkan adanya sikap keterbukaan, penerimaan, dan tidak memberikan penilaian. Mindfulness berkaitan dengan pemberian atensi pada momen masa kini, dimana hal ini merupakan inti dari aspek psikologis dalam performa puncak pada olahraga (Ravizza 2002 dalam Bernier dkk., 2009). Kabat-Zinn (2013) menyatakan bahwa terdapat 7 sikap dasar yang harus dimiliki individu untuk mencapai mindfulness, yakni non-judging, patience, beginner's mind, trust, non-striving, acceptance, dan letting go.

Pada dimensi non-judging, Kabat-Zinn (2013) menjelaskan bahwa dimensi ini ditunjukkan dengan kemampuan individu untuk memperhatikan pengalaman masa kini dari momen ke momen tanpa memberikan penilaian berdasarkan pada opini dan pemikiran yang sudah dimiliki sebelumnya. Kedua partisipan mampu untuk tidak memberikan penilaian negatif kepada dirinya sendiri atas kegagalan yang dialami saat sedang tampil di pertandingan dan hanya berfokus untuk melakukan gerakan selanjutnya sembari melakukan visualisasi gerakan. Selain itu, LF mampu untuk tidak memberikan penilaian negatif terhadap dirinya yang dapat membuat pikirannya terdistraksi saat akan melakukan gerakan yang mengarah ke belakang, dimana ia memiliki trauma terhadap gerakan mengarah ke belakang. Sedangkan partisipan TM mampu menenangkan diri agar fokus terhadap diri dan gerakan yang ia ambil saat bertanding, meski awalnya ia mudah terdistraksi dengan penampilan lawan yang memunculkan adanya pemikiran negatif terhadap kemampuan dirinya. Hal ini sesuai dengan pernyataan Gardner dam Moore (2007 dalam Permadi \& Nurwianti, 2019) yang mengatakan bahwa 
seorang atlet harus mampu meminimalisir adanya self-judgement jika ingin menampilkan performa yang baik saat bertanding.

Dimensi patience menekankan pada kemampuan individu untuk tetap berada dan menikmati setiap momen kecil di masa kini serta memahami bahwa tidak semua hal dalam hidup dapat diburu-buru (Kabat-Zinn, 2013). Kedua partisipan cenderung akan merasa gugup pada hari pertandingan yang menyebabkan kedua partisipan tidak dapat fokus, tangan dingin, maupun kaki gemetar. Namun menjelang tampil, keduanya mampu mengontrol diri untuk berfokus pada momen masa kini dimana keduanya harus melakukan rangkaian gerakan. Partisipan LF menenangkan diri dengan cara menyendiri dan mendengarkan musik, sedangkan TM menenangkan diri dengan cara mengatur pola napas. Proses kedua partisipan dalam menenangkan diri ini menunjukkan adanya proses untuk menjadi mindful terhadap kegiatan yang dilakukan. Dengan menjadi mindful, memiliki arti bahwa individu mampu untuk sadar akan masa kini, terlepas dari kejadian masa lalu maupun masa yang akan datang (Mace, 2008). Individu yang mampu untuk mindful tidak berusaha untuk menekan suatu pengalaman yang dialami saat ini, juga tidak melakukan defense terhadap pengalaman tersebut, melainkan menerima, mengobservasi, dan mendeskripsikan pengalaman tanpa mengelaborasi apa yang terjadi (Bishop dkk., 2006).

Partisipan LF dan TM mampu memusatkan fokus pada dirinya, memvisualisasikan, dan melakukan gerakan demi gerakan tanpa tergesa-gesa. Bahkan ketika gagal mengambil gerakan atau terjatuh, keduanya mampu untuk mengontrol dirinya untuk berusaha lebih fokus dan lebih tenang dari sebelumnya. Hal ini sesuai dengan pernyataan Gardner dan Moore (2007 dalam Permadi \& Nurwianti, 2019) yang mengatakan bahwa seorang atlet yang ingin menampilkan performa ideal atau performa terbaiknya harus berfokus pada tugasnya sebagai atlet yang sedang berkompetisi, bukan berfokus pada pemikiran dan emosi diri mereka sendiri.

Partisipan LF pernah melakukan gerakan senam tanpa sadar dan mengakibatkan ia mengalami cedera dan menjadi trauma terhadap gerakan-gerakan yang mengarah ke belakang. Begitu pula dengan partisipan TM yang pernah beberapa kali melakukan gerakan secara tidak sadar. Walaupun begitu, ia mengatakan bahwa tubuhnya dapat secara otomatis melakukan gerakan senam meski ia tidak dapat mengontrolnya. Namun otomatisasi gerakan ini tidak selalu membuatnya berhasil melakukan gerakan senam, terkadang gerakan tersebut bisa gagal diambil olehnya.

Partisipan LF yang memiliki trauma terhadap gerakan ke belakang ini tetap bisa melakukan gerakan tersebut apabila ia fokus hanya melakukan gerakan tersebut dan mampu untuk tidak berpikiran negatif. Sedangkan pada partisipan TM yang pernah berada pada titik terendah dalam hidupnya ketika harus melakukan operasi pasca cedera yang ia alami ini mampu belajar untuk berdamai dengan dirinya sendiri dan menikmati segala proses yang terjadi dalam hidupnya, meski awalnya melakukan penolakan terhadap apa yang terjadi. Ia pun paham bahwa setiap hal yang terjadi memiliki alasan dan waktunya masing-masing untuk terjadi.

Pada dimensi beginner's mind, Kabat-Zinn (2013) menjelaskan bahwa dimensi ini merupakan kemampuan individu untuk melihat segala hal seakan sebagai sesuatu yang baru dialami sehingga individu akan menanggalkan segala ekspektasi yang sudah dimiliki sebelumnya. Individu akan lebih terbuka terhadap segala kemungkinan yang terjadi serta menjadi penasaran terhadap apa yang menanti mereka selanjutnya. Kedua partisipan menunjukkan bahwa ketika sedang tampil di pertandingan, keduanya akan terfokus pada diri dan gerakan dengan memvisualisasikan gerakan satu per satu. Dalam kondisi ini, kedua partisipan tidak memberikan ekspektasi terhadap hal-hal di luar gerakan-gerakan rangkaian. Pikiran yang sedang terfokus pada pengalaman masa kini dan tidak terbawa ke pikiran akan 
masa lalu maupun masa yang akan datang, serta tidak membawa penilaian berdasarkan opini atas pemikiran yang telah dimiliki sebelumnya menandakan bahwa pikiran sedang dalam kondisi yang terbuka, menerima keadaan sebagaimana adanya, dan terbebas dari kebiasaan seorang yang ahli (experts) (Kabat-Zinn, 2013). Hal ini berarti bahwa individu mampu untuk menjalani pengalaman masa kini selayaknya orang awam yang memiliki rasa ingin tahu tinggi tanpa menunggu sesuatu yang diinginkan menjadi kenyataan, sehingga memungkinkan individu untuk tetap berada pada masa kini.

Pada dimensi trust, Kabat-Zinn (2013) memaparkan bahwa individu harus mampu untuk percaya baik pada kemampuan diri, kekuasaan diri, maupun intuisi dirinya sendiri, meski melakukan "kesalahan" dalam suatu hal. TM mudah merasa gugup sehingga mudah terdistraksi dengan pemikiran negatif, seperti tidak yakin akan kemampuan diri sendiri, setelah melihat kemampuan lawan. Hal ini sesuai dengan pernyataan Gardner dan Moore (2004) yang menyatakan bahwa permasalahan yang sering muncul pada atlet ketika berada di situasi pertandingan adalah atlet lebih berfokus dan memberi perhatian yang lebih pada hal-hal di luar tugas atau kompetisi tersebut. Partisipan LF dengan sengaja tidak mau melihat penampilan lawan sebelum ia selesai tampil. Hal ini diakukan agar ia tidak terdistraksi dengan pemikiran-pemikiran akan gerakan lawannya. Begitu pula ketika ia mendapatkan tekanan dari pelatih terkait dengan target yang harus dicapai di pertandingan. Gardner dan Moore (2004) menyatakan bahwa adanya tekanan yang berlebihan dapat memicu munculnya kecemasan pada atlet. Ketika tiba waktunya untuk tampil, kedua partisipan menunjukkan kemampuan mereka untuk percaya pada kekuasaan dan kemampuan diri mereka meski sempat terjatuh atau gagal mengambil gerakan saat tampil di pertandingan.

Dimensi non-striving merupakan sikap dimana individu mampu untuk merangkul dan mempertahankan kondisi kesadarannya tanpa berusaha untuk mencapai sebuah tujuan dari suatu hal (Kabat-Zinn, 2013). Kedua partisipann pada mulanya masih merasa gugup dan mencoba untuk menenangkan diri dengan caranya masing-masing. Partisipan LF menenangkan diri dengan berdiam diri dan mendengarkan musik, sedangkan TM menenangkan diri dengan cara mengatur pernapasan. Dalam proses menenangkan diri ini, keduanya tidak berusaha untuk mendapatkan hasil dari tujuan tertentu, melainkan mencoba menenangkan diri agar dapat berfokus hanya kepada momen masa kini dimana kedua subjek harus melakukan gerakan-gerakan senam di pertandingan tanpa terdistraksi terhadap hal-hal lain. Keduanya juga mampu untuk berfokus pada diri dan gerakan satu per satu dan mampu untuk tetap melanjutkan ke gerakan selanjutnya meski sempat terjatuh atau gagal mengambil gerakan. Hal ini sesuai dengan penjelasan Kabat-Zinn (2013) yang menyatakan bahwa dalam dimensi non-striving, individu hanya perlu menjalani pengalaman dari momen ke momen tanpa adanya hasrat untuk mencapai sesuatu. Selain itu, individu juga harus menyadari bahwa segala hal yang sudah terjadi saat ini sudah cukup baik walaupun bukan hal yang menyenangkan pada masa kini, namun hal tersebut sudahlah cukup.

Dimensi acceptance memaparkan tentang bentuk penerimaan individu bahwa individu bersedia melihat segala sesuatu terjadi sebagaimana adanya dan tanpa adanya penolakan atau penyangkalan (Kabat-Zinn, 2013). Kedua partisipan, baik LF maupun TM tidak melakukan penyangkalan atau penolakan terhadap kegagalan yang ia alami saat sedang tampil di pertandingan. Keduanya tetap dapat fokus untuk melanjutkan ke gerakan-gerakan selanjutnya walau sebelumnya sempat terjatuh atau gagal mengambil gerakan.

Dalam konteks yang lain, partisipan TM yang mengalami cedera dan menyebabkan harus mengundurkan diri dari tim Pelatnas untuk SEA Games 2019 dan menjalani operasi sebanyak dua kali ini pada awalnya ia menolak menerima kenyataan bahwa kejadian tersebut membuat rencana karir atlet yang sudah ia susun sebelumnya menjadi hancur berantakan. Selama beberapa waktu ia lebih 
banyak bersedih karena hal tersebut. Dalam kondisi yang terpuruk tersebut partisipan TM meluapkan keluh kesahnya dengan keluarga dan juga kerabat dekatnya. Ia mendapatkan nasihat yang membuat dirinya tersadar bahwa dirinya harus selalu melihat sisi positif dari kejadian yang terjadi. Sejak saat itu partisipan TM mulai belajar untuk berdamai dengan dirinya sendiri serta menerima bahwa segala sesuatu terjadi sebagaimana adanya dan tidak lagi memberikan penyangkalan terhadap hal-hal yang terjadi dalam hidupnya.

Dimensi letting go merupakan kondisi dimana individu mampu untuk tidak terikat atau terlepas dari pikiran, perasaan, maupun situasi yang pada pengalaman yang terjadi dan menerima segala sesuatu sebagaimana adanya (Kabat-Zinn, 2013). Kabat-Zinn (2013) menyatakan bahwa ketika mulai memberikan perhatian terhadap pengalaman batin, individu cenderung akan dengan cepat menemukan bahwa ada pikiran, perasaan, dan situasi tertentu yang ingin dipertahankan. Hal ini dapat membuat individu terlepas dari fokusnya terhadap masa kini dan menuju ke masa lalu maupun masa yang akan datang. Kedua partisipan mampu untuk melepaskan pemikiran mengenai hal-hal negatif yang dapat membuat pikirannya terdistraksi serta tidak terjebak dalam perasaan gugup yang ia rasakan ketika keduanya mencoba menenangkan diri di pertandingan. Partisipan LF dan TM juga menunjukkan bahwa keduanya mampu untuk tetap menguasai diri agar tetap fokus melakukan gerakan-gerakan selanjutnya hingga rangkaian selesai. Keduanya mampu untuk tidak larut dalam pikiran, perasaan, maupun situasi saat terjatuh atau gagal mengambil gerakan di pertandingan.

Pada konteks lainnya, partisipan LF yang memiliki rasa trauma terhadap gerakan yang mengarah ke belakang ini mampu untuk melepaskan pemikiran dan perasaan terhadap trauma yang ia alami ketika diharuskan untuk melakukan gerakan-gerakan yang mengarah ke belakang. Sedangkan partisipan TM yang mengalami cedera sesaat sebelum jadwal tandingnya di SEA Games 2019 dan mengharuskan ia melakukan operasi sebanyak dua kali ini awalnya tidak dapat menerima kenyataan bahwa kejadian tersebut menyebabkan semua rencana karir yang telah ia buat menjadi berantakan. Pikiran untuk menyerah terhadap karirnya sebagai atlet pun pernah terlintas di pikirannya. Saat itu ia masih belum bisa melepaskan pikiran dan perasaan sedihnya terhadap apa yang menimpa dirinya. Namun, setelah ia mendapat nasihat dari keluarga maupun kerabat dekatnya bahwa ia perlu melihat sisi positif dari semua kejadian yang terjadi dalam hidupnya, ia pun tersadar dan mulai belajar untuk menerima keadaan meski sedang berada dalam titik terendah dalam hidupnya. Ia mampu untuk melepaskan pemikiran dan perasaan sedih dan kecewa terhadap kejadian yang dialaminya serta situasi yang menimpa dirinya.

\section{S I M P U L A N}

Penelitian ini bertujuan untuk mengetahui gambaran mindfulness pada atlet senam artistik putri Jawa Timur. Hasil penelitian menunjukkan bahwa kedua partisipan mampu untuk mindful ketika sesaat sebelum tampil di pertandingan, saat tampil di pertandingan, saat harus menghadapi trauma terkait dengan gerakan senam, maupun saat menjalani masa rehabilitasi pasca cedera. Namun, keduanya juga menunjukkan adanya inkonsistensi dalam usahanya untuk menjadi mindful, baik ketika berlatih maupun bertanding. Berdasarkan penelitian ini, diharapkan pelatih dapat menjadikannya sebagai acuan untuk membuat program latihan bagi atlet dan dapat meminta dampingan dari psikolog profesional terkait dengan treatment yang dapat diberikan pada atlet sejak dini sebagai bentuk tindakan preventif, seperti pelatihan mindfulness. Untuk penelitian selanjutnya, diharapkan dapat mencari partisipan dengan latar belakang olahraga dan rentang usia yang berbeda agar dapat memperkaya data mengenai mindfulness pada olahraga. 


\section{U C A P A N T ER I MAKASIH}

Penulis mengucapkan terima kasih kepada pihak-pihak yang telah membantu dalam proses penyelesaian penelitian ini, terutama kepada segenap sivitas akademika Fakultas Psikologi Universitas Airlangga, rekan-rekan Psikologi Universitas Airlangga 2015, para partisipan penelitian, serta pihakpihak lain yang terkait dalam proses penelitian juga mendukung hingga penelitian berakhir.

\section{DEKLARAS I POTENSI TER JADINYA KONFLIK KEPENTINGAN}

Alya Afani dan Afif Kurniawan tidak bekerja, menjadi konsultan, memiliki saham, atau menerima dana dari perusahaan atau organisasi manapun yang mungkin akan mengambil untung dari diterbitkannya naskah ini.

\section{PUSTAKA ACUAN}

Aka, B. A. (2009). Cerdas dan Bugar dengan Senam Lantai. Grasindo.

Baer, R. A., Smith, G. T., Hopkins, J., Krietemeyer, J., \& Toney, L. (2006). Using Self-Report Assessment Methods to Explore Facets of Mindfulness. Assessment, 13(1), 27-45. https://doi.org/10.1177/1073191105283504

Bernier, M., Thienot, E., Codron, R., \& Fournier, J. F. (2009). Mindfulness and Acceptance Approaches in Sport Performance. Journal of Clinical Sport Psychology, 3(4), 320-333. https://doi.org/10.1123/jcsp.3.4.320

Birrer, D., Röthlin, P., \& Morgan, G. (2012). Mindfulness to Enhance Athletic Performance: Theoretical Considerations and Possible Impact Mechanisms. Mindfulness, 3(3), 235-246. https://doi.org/10.1007/s12671-012-0109-2

Bishop, S. R., Lau, M., Shapiro, S., Carlson, L., Anderson, N. D., Carmody, J., Segal, Z. V., Abbey, S., Speca, M., Velting, D., \& Devins, G. (2006). Mindfulness: A Proposed Operational Definition. Clinical Psychology: Science and Practice, 11(3), 230-241. https://doi.org/10.1093/clipsy.bph077

Boyatzis, R. E. (1998). Transforming Qualitative Information: Thematic Analysis and Code Development. Sage Publications.

Brown, K. W., \& Ryan, R. M. (2003). The benefits of being present: Mindfulness and its role in psychological well-being. Journal of Personality and Social Psychology, 84(4), 822-848. https://doi.org/10.1037/0022-3514.84.4.822

Chase, M. A., Magyar, T. M., \& Drake, B. M. (2005). Fear of injury in gymnastics: Self-efficacy and psychological strategies to keep on tumbling. Journal of Sports Sciences, 23(5), 465-475. https://doi.org/10.1080/02640410400021427 
Gardner, F. L., \& Moore, Z. E. (2004). A mindfulness-acceptance-commitment-based approach to athletic performance enhancement: Theoretical considerations. Behavior Therapy, 35(4), 707-723. https://doi.org/10.1016/S0005-7894(04)80016-9

Giluk, T. L. (2009). Mindfulness, Big Five personality, and affect: A meta-analysis. Personality and Individual Differences, 47(8), 805-811. https://doi.org/10.1016/j.paid.2009.06.026

Herdiansyah, H. (2015). Metodologi Penelitian Kualitatif untuk Ilmu-Ilmu Sosial. Salemba Humanika.

Josefsson, T., Ivarsson, A., Gustafsson, H., Stenling, A., Lindwall, M., Tornberg, R., \& Böröy, J. (2019). Effects of Mindfulness-Acceptance-Commitment (MAC) on Sport-Specific Dispositional Mindfulness, Emotion Regulation, and Self-Rated Athletic Performance in a Multiple-Sport Population: An RCT Study. Mindfulness, 10(8), 1518-1529. https://doi.org/10.1007/s12671019-01098-7

Kabat-Zinn, J. (2013). Full Catastrophe Living: Using The Wisdom of Your Body and Mind to Face Stress, Pain, and Illness (Revised and updated edition). Bantam Books trade paperback.

Kaiseler, M., Poolton, J. M., Backhouse, S. H., \& Stanger, N. (2017). The Relationship Between Mindfulness and Life Stress in Student-Athletes: The Mediating Role of Coping Effectiveness and Decision Rumination. The Sport Psychologist, 31(3), 288-298. https://doi.org/10.1123/tsp.2016-0083

Kerr, Z. Y., Marshall, S. W., Dompier, T. P., Corlette, J., Klossner, D. A., \& Gilchrist, J. (2015). College SportsRelated Injuries-United States, 2009-10 Through 2013-14 Academic Years. MMWR. Morbidity and Mortality Weekly Report, 64(48), 1330-1336. https://doi.org/10.15585/mmwr.mm6448a2

Legard, R., Keegan, J., \& Kit, W. (2003). In-depth Interviews. Dalam J. Ritchie \& J. Lewis, Qualitative Research Practice: A Guide for Social Science Students and Researchers (hlm. 139-168). Sage.

Mace, C. (2008). Mindfulness and Mental Health. Routledge.

Meeusen, R., \& Borms, J. (1992). Gymnastic Injuries: Sports Medicine, 13(5), 337-356. https://doi.org/10.2165/00007256-199213050-00004

Permadi, D., \& Nurwianti, F. (2019). Mindfulness and Coping Skills as Predictors of Competitive Anxiety amongst Athletes in Indonesia. ANIMA Indonesian Psychological Journal, 33(4). https://doi.org/10.24123/aipj.v33i4.1796

Poerwandari, E. K. (2007). Pendekatan Kualitatif untuk Penelitian Perilaku Manusia. LPSP3 Fakultas Psikologi Universitas Indonesia.

Ritchie, J., Lewis, J., \& Elam, G. (2003). Designing and Selecting Samples. Dalam J. Ritchie \& J. Lewis, Qualitative Research Practice: A Guide for Social Science Students and Researchers. Sage. 
Sukamti, E. R., \& Hidayat, I. T. (2010). Upaya Pelatih dalam Mengatasi Kecemasan Atlet Senam Sebelum Perlombaan pada Pekan Olahraga Pelajar Nasional 2009. 6(2), 100-109. 